\title{
Validation of stratospheric water vapour measurements from the airborne microwave radiometer AMSOS
}

\author{
S. C. Müller ${ }^{1}$, N. Kämpfer ${ }^{1}$, D. G. Feist ${ }^{2}$, A. Haefele ${ }^{1}$, M. Milz ${ }^{3}{ }^{*}$, N. Sitnikov ${ }^{4}$, C. Schiller ${ }^{5}$, C. Kiemle ${ }^{6}$, and J. Urban ${ }^{7}$ \\ ${ }^{1}$ University of Bern, Bern, Switzerland \\ ${ }^{2}$ Max-Planck-Institute for Biogeochemistry, Jena, Germany \\ ${ }^{3}$ Institut für Meteorologie und Klimaforschung, Karlsruhe, Germany \\ ${ }^{4}$ Central Aerological Observatory, Moscow Region, Russia \\ ${ }^{5}$ Forschungszentrum Jülich GmbH, Jülich, Germany \\ ${ }^{6}$ DLR, Institut fuer Physik der Atmosphaere, Oberpfaffenhofen, Germany \\ ${ }^{7}$ Chalmers University of Technology, Göteborg, Sweden \\ * now at: Luleå Technical University, Kiruna, Sweden
}

Received: 13 November 2007 - Published in Atmos. Chem. Phys. Discuss.: 25 January 2008

Revised: 19 May 2008 - Accepted: 26 May 2008 - Published: 24 June 2008

\begin{abstract}
We present the validation of a water vapour dataset obtained by the Airborne Microwave Stratospheric Observing System AMSOS, a passive microwave radiometer operating at $183 \mathrm{GHz}$. Vertical profiles are retrieved from spectra by an optimal estimation method. The useful vertical range lies in the upper troposphere up to the mesosphere with an altitude resolution of 8 to $16 \mathrm{~km}$ and a horizontal resolution of about $57 \mathrm{~km}$. Flight campaigns were performed once a year from 1998 to 2006 measuring the latitudinal distribution of water vapour from the tropics to the polar regions. The obtained profiles show clearly the main features of stratospheric water vapour in all latitudinal regions. Data are validated against a set of instruments comprising satellite, ground-based, airborne remote sensing and in-situ instruments. It appears that AMSOS profiles have a dry bias of 0 to $-20 \%$, when compared to satellite experiments. Also a comparison between AMSOS and in-situ hygrosondes FISH and FLASH have been performed. A matching in the short overlap region in the upper troposphere of the lidar measurements from the DIAL instrument and the AMSOS dataset allowed water vapour profiling from the middle troposphere up to the mesosphere.
\end{abstract}

Correspondence to: S. C. Müller (stefan.mueller@mw.iap.unibe.ch)

\section{Introduction}

Water vapour is important for our environment and climate. It is a key element in the radiative budget of the earth's atmosphere and contributes the largest to the greenhouse effect due to strong absorption in the troposphere. In the stratosphere water vapour is a source for the formation of polar stratospheric clouds and the $\mathrm{OH}$ radical molecule and thus it is involved in the process of ozone depletion. In the mesosphere it is destroyed by photolysis. As a long-lived and variable trace gas it provides the possibility to study atmospheric motion. The importance of knowledge about this key parameter is evident (SPARC, 2000) (WMO, 2007).

A very common technique to measure water vapour is by passive remote sensing in the infrared or microwave regions by satellite, aircraft or ground-based instruments. Other techniques use in-situ sensors FISH (Zöger et al., 1999) and FLASH (Sitnikov et al., 2007) or Frost-PointHygrometers (Vömel et al., 2007) from balloon or aircraft, or active remote sensing with differential absorption lidar (Ehret et al., 1999). Satellite observations have been made by UARS/HALOE (Russell III et al., 1993), UARS/MLS (Lahoz et al., 1996), ERBS/SAGE-II (Chiou et al., 1997), SPOT4/POAM-III (Lucke et al., 1999), AURA/MLS (Schoeberl et al., 2006), ENVISAT/MIPAS (Fischer et al., 2008) and Odin/SMR (Urban et al., 2007) over the last two decades and deliver an excellent three dimensional global coverage of the water vapour distribution. From aircraft a two dimensional section of the water vapour distribution in the

Published by Copernicus Publications on behalf of the European Geosciences Union. 


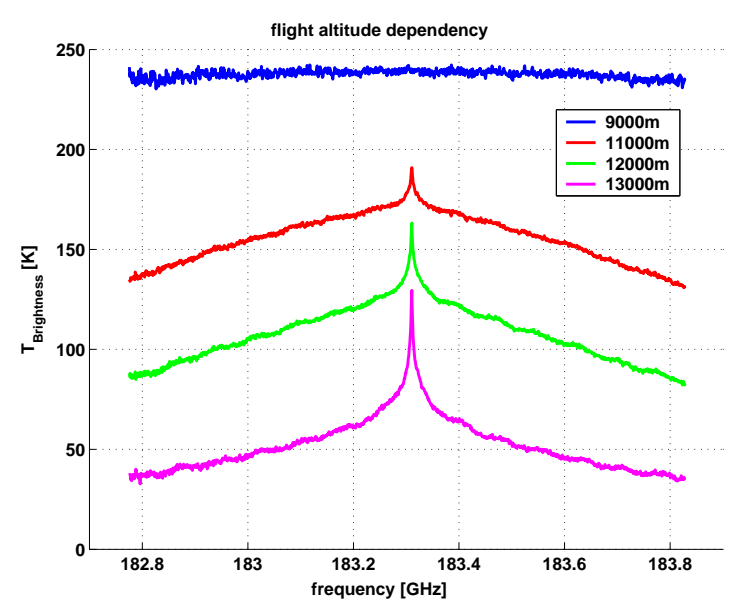

Fig. 1. A set of spectra measured at different altitudes in the tropics during the ascent of the aircraft in November 2005. At $9 \mathrm{~km}$ the water vapour line at $183.31 \mathrm{GHz}$ is saturated and does not allow stratospheric $\mathrm{H}_{2} \mathrm{O}$ retrieval.

atmosphere along the flighttrack is obtained. Because stratospheric water vapour has a latitudinal dependence the main distribution patterns can be measured by a flight from northern latitudes to the tropics. Ground-based (Deuber et al., 2004) (Nedoluha et al., 1995) or balloon soundings determine the one-dimensional distribution on a continuous time basis and thus are very interesting for local trend analyses.

With the Airborne Microwave Stratospheric Observing System (AMSOS), carried by a Learjet-35A of the Swiss Airforce, we measured the latitudinal distribution of water vapour from the tropics to the north pole during one week per year from 1998 to 2006. A former version of the instrument had been flown from 1994 to 1996 (Peter, 1998). The instrument was flown in spring or autumn during active stratospheric periods due to the change between polar nighttime and day-time. Measurements inside the polar vortex as well as in the tropics including one overflight of the equator were accomplished. The dataset overlaps several satellite experiments in time. In a previous work (Feist et al., 2007) this dataset was compared to the ECMWF model.

In this paper we first present the AMSOS retrieval characteristic of the version 2.0 data and the 9-year AMSOS water vapour climatology of the northern hemisphere. Secondly the validation of the data which has been performed against already validated datasets from satellite experiments (Harries et al., 1996), (Rind et al., 1993), (Nedoluha et al., 2002), (Milz et al., 2005), (Raspollini et al., 2006) and the ground-based station MIAWARA (Deuber et al., 2005) for the whole profile range, as well as with in-situ and lidar measurements in the Upper Troposphere-Lower Stratosphere (UTLS) region. The advantage of this dataset is its coverage of all latitudes from $-10^{\circ}$ to $90^{\circ}$ North for the UTLS region up to the mesosphere for early spring and autumn periods with a good horizontal resolution of $57 \mathrm{~km}$. The data are useful for studies of atmospheric processes and validation. The profiles are available for download at http: //www.iapmw.unibe.ch/research/projects/AMSOS.

\section{AMSOS water vapour measurement and retrieval}

\subsection{Measurement method}

AMSOS measures the rotational emission line of water vapour at $183.3 \pm 0.5 \mathrm{GHz}$ (Vasic et al., 2005) by up-looking passive microwave radiometry (Janssen, 1993). Performing observations at this frequency is dependent on atmospheric opacity. Figure 1 shows a set of spectra measured at different flight altitudes during the ascent of the aircraft over the tropics. Under humid conditions, as encountered in the tropics, the line is saturated up to an altitude of more than $9 \mathrm{~km}$. On the other hand in polar regions it is possible to make good quality measurements at flight levels down to approximately $4 \mathrm{~km}$. Under very dry conditions in the winter months it is also possible to retrieve stratospheric water vapour from the alpine research station Jungfraujoch in Switzerland at $3.5 \mathrm{~km}$ altitude for about seven percent of the time (Siegenthaler et al., 2001).

The AMSOS instrument was flown with a broadband Accousto-Optical Spectrometer (AOS) of $1 \mathrm{GHz}$ bandwidth during all missions, a broadband digital FFT spectrometer with the same bandwidth and a narrowband digital FFT spectrometer with bandwidth of $25 \mathrm{MHz}$ only in 2005 and 2006. In this work only profiles from the AOS are presented.

\subsection{AMSOS profile retrieval setup, characteristic and error analysis}

For the retrieval of water vapour profiles from the measured spectra we need knowledge of the relationship between the atmospheric state $x$ and the measured signal $y$. This is described by the forward model function F (Eq. 1). To find a solution for the inverse problem, we use the optimal estimation method (OEM) according to Rodgers (Rodgers, 2000). The forward model is split up in a radiative transfer part $\mathrm{F}_{r}$ calculated by the Atmospheric Radiative Transfer Simulator (ARTS) (Buehler et al., 2005) and a sensor modelling part $\mathrm{F}_{s}$ which is done by the software package Qpack (Eriksson et al., 2005). The implementation of the retrieval algorithm is also done by Qpack. Forward model parameters $b$ include the instrument influencing the measurement, namely antenna beam pattern, sideband filtering, observation angle, attenuation due to the aircraft window, standing waves, as well as atmospheric parameters, like pressure and temperature profiles, other species, spectral parameters and line shape. $\epsilon$ is the measurement noise.

$y=\mathrm{F}(x, b)+\epsilon=\mathrm{F}_{s}\left[\mathrm{~F}_{r}(x, b)\right]+\epsilon$ 
Profile from 2002-09-17 08:15:56, 83N 11E
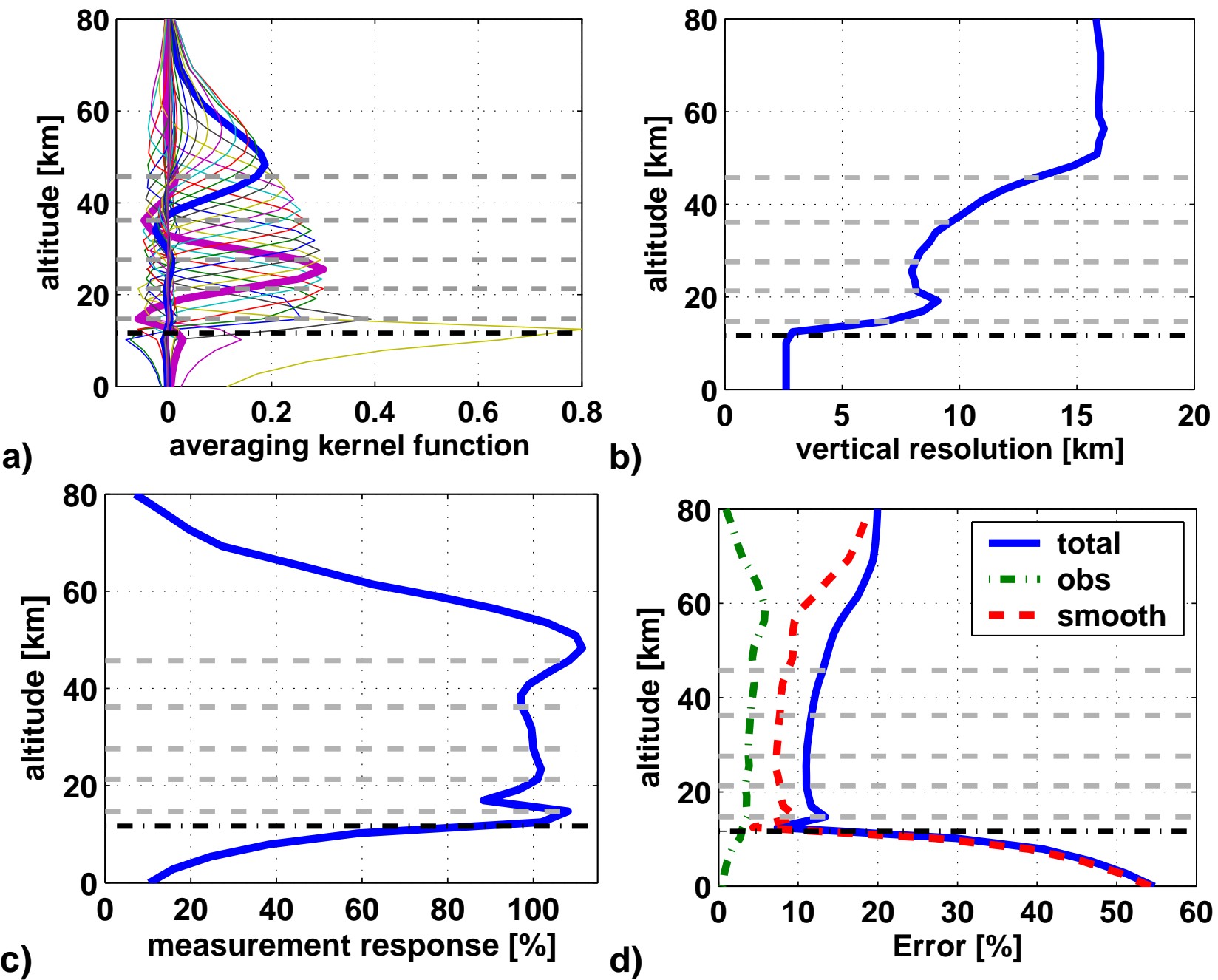

Fig. 2. Characterisation of the AMSOS retrieval with the averaging kernel functions. With the black dashed-dotted line the flight altitude is marked. The gray dashed lines mark the independent layers. To make the width of the averaging kernel functions directly visible, two functions are plotted as thick lines (a). The vertical resolution is between $8-16 \mathrm{~km}$, and increases with altitude (b). AMSOS profiles for an altitude range between 15 and $60 \mathrm{~km}$ can be retrieved from the AOS spectrometer as seen in the measurement response (c). The total error (total=smoothing+observation) is less than $20 \%$ for the useful part of the profile (d).

Inverse problems are often ill-posed and lead to a best estimate $\hat{x}$ of the real state by minimising the so called costfunction

$$
(y-\mathrm{F}(x, b))^{\mathrm{T}} \mathbf{S}_{y}^{-1}(y-\mathrm{F}(x, b))+\left(x-x_{a}\right)^{\mathrm{T}} \mathbf{S}_{x}^{-1}\left(x-x_{a}\right)
$$

with the help of apriori information $x_{a}$ of the retrieval quantity $x$, the measured spectrum $y$ and their covariance matrices $\mathbf{S}_{x}$ and $\mathbf{S}_{y}$. The best estimate $\hat{x}$ is found by an iterative process with the Marquardt-Levenberg approach.

$$
\begin{aligned}
x_{i+1}= & x_{i}+\left(\mathbf{S}_{x}^{-1}+\mathbf{K}_{i}^{T} \mathbf{S}_{y}^{-1} \mathbf{K}_{i}+\gamma \mathbf{D}\right)^{-1} \\
& \left\{\mathbf{K}_{i}^{T} \mathbf{S}_{y}^{-1}\left[y-\left[\mathrm{F}\left(x_{i}\right)\right]-\mathbf{S}_{x}^{-1}\left[x_{i}-x_{a}\right]\right\}\right.
\end{aligned}
$$

where $\mathbf{K}_{i}=\frac{\partial \mathrm{F}\left(x_{i}, b\right)}{\partial x_{i}}, \gamma$ a trade-off parameter and $\mathbf{D}$ a diagonal scaling matrix.

The character of a retrieval is derived from the averaging kernel matrix $\mathbf{A}=\mathbf{A}\left(\mathbf{K}, \mathbf{S}_{x}, \mathbf{S}_{y}\right) . \quad \mathbf{A}=\frac{\partial \hat{x}}{\partial x}$ describes the sensitivity of the retrieved profile to the true state. A also provides information about the measurement response that is a measure of how much the retrieved profile depends on the measurement and how much on the apriori profile by taking the integral over A. Another term often used in this context is the apriori contribution. The sum of measurement response and apriori contribution is 1 . The full width at half maximum of each averaging kernel function, represented by a row in the matrix A, provides the vertical resolution. A typical 


\section{Apriori covariance matrix $S_{x}$}

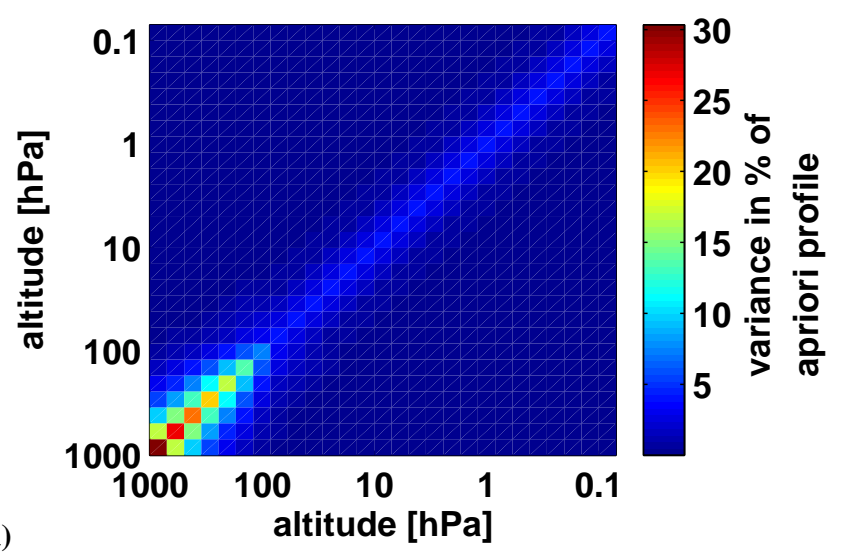

(a)

\section{Standard deviation ERA40 monthly means}

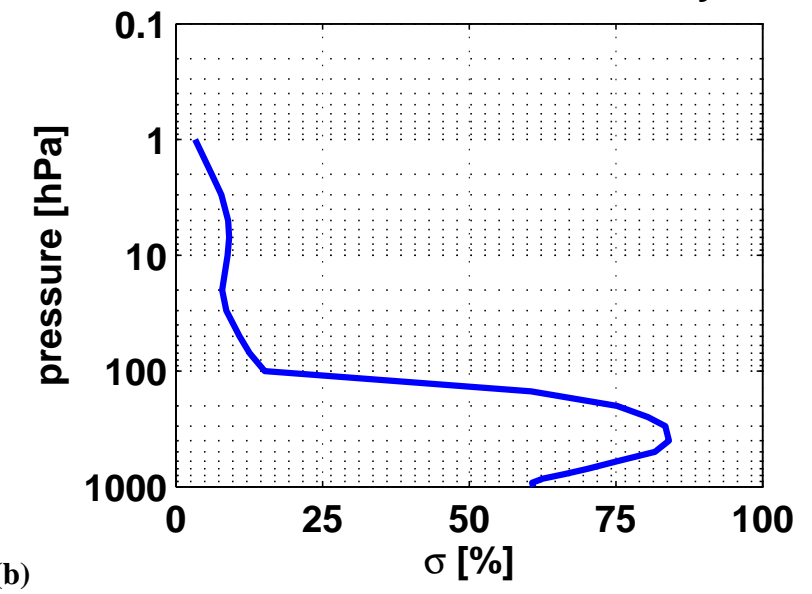

Fig. 3. (a) Apriori covariance matrix used for the AMSOS retrievals. (b) Standard deviation of the ERA40 monthly mean profiles.

averaging kernel matrix $\mathbf{A}$, the meaurement response and the vertical resolution of a retrieval from AMSOS is shown in Fig. 2a-c. Between approximately the flight altitude and $60 \mathrm{~km}$ the measurement response is more than $80 \%$. The vertical resolution ranges between $8-16 \mathrm{~km}$ increasing with altitude. The trace of $\mathbf{A}$ is an indicator for the number of independent points in the profile and is between 4-6 for AMSOS. They are marked by the dashed gray lines in Fig. 2. There is one layer in the troposphere and one in the mesosphere, the remaining four are in the stratosphere. Qpack takes into consideration the model uncertainties and the measurement error and the error of the apriori profile, called the smoothing error. The total error (total=observation+smoothing) is in the order of $10-15 \%$ for the altitudes with apriori contribution less than $20 \%$ (Fig. 2d). The observation error is due to the remaining thermal noise on the spectrum and the smoothing error part is due to the covariance of the apriori information. The smoothing error part is almost the double of the observation error.
2.3 Water vapour apriori information, covariance matrix and model parameters

An important issue for processing our AMSOS dataset was the selection of an appropiate apriori water vapour profile to constrain the retrieval algorithm to a reasonable solution. We made the choice to use a global mean of monthly means of the ERA40 climatology from ECMWF from ground up to $45 \mathrm{~km} . \mathrm{H}_{2} \mathrm{O}$ vmr profiles from ERA40 were derived from the specific humidity field according standard conversion equations. To build the mean profile we introduced a latitudinal weight to avoid an overweight of polar profiles since the number of ECMWF grid points per latitude is constant. Out of the statistic of these 425000 profiles we set up the covariance matrix $\mathbf{S}_{x}$ as shown in Fig. 3a. The standard deviation (Fig. $3 b$ ) in the stratosphere is lower than $10 \%$ and in the troposphere it raises up to $80 \%$. This change is directly visible in the diagonal elements of the coavriance matrix $\mathbf{S}_{x}$. For altitudes above the ERA40 grid we used the US-Standard Atmosphere (US Committee on Extension to the Standard Atmosphere, 1976) as apriori information. The change is done at the intersection point of the ERA40 profile and the USStandard profile in about $45 \mathrm{~km}$ altitude. From an earlier study (Feist et al., 2007) we know that ERA40 values at the top of the stratosphere diverge from observations.

For the temperature and pressure profiles we used data from ECMWF continued by CIRA86 (Rees et al., 1990) for the altitude levels above the top of the ECMWF atmosphere. Spectral parameters are taken from the HITRAN96 (Rothman et al., 1998) molecular spectroscopy database.

Additionally a baseline which originates from a standing wave between the mixer and the aircraft window, resulting in a sinusoidal modulation of the spectrum with a frequency of $75 \mathrm{MHz}$, and a constant offset of the spectrum is retrieved.

\subsection{Spectra pre-integration}

To reduce thermal noise to approximately $1 \%$ before retrieving a profile we had to pre-integrate several spectra. It is important to integrate spectra that were measured under similiar conditions. The most critical parameters that could change quickly during flight are the flight altitude and the instrument's elevation angle. The elevation angle depends on the aircraft's roll angle as well as the position of the instrument's mirror elevation angle. Only spectra with a maximum roll angle difference of $\pm 0.1^{\circ}$, a mirror elevation of $\pm 0.1^{\circ}$ and a flight altitude within $\pm 100 \mathrm{~m}$ were integrated. To avoid integration of spectra over a too large distance, the spectra were only considered if they were measured within $10 \mathrm{~min}$. This selection finally determines the horizontal resolution along the track of $57 \mathrm{~km} \pm 30 \mathrm{~km}$ of the AMSOS dataset. The remaining noise that overlay the spectrum determines the diagonal elements of the covariance matrix of the measurement error of $\mathbf{S}_{y}$. 
(a)
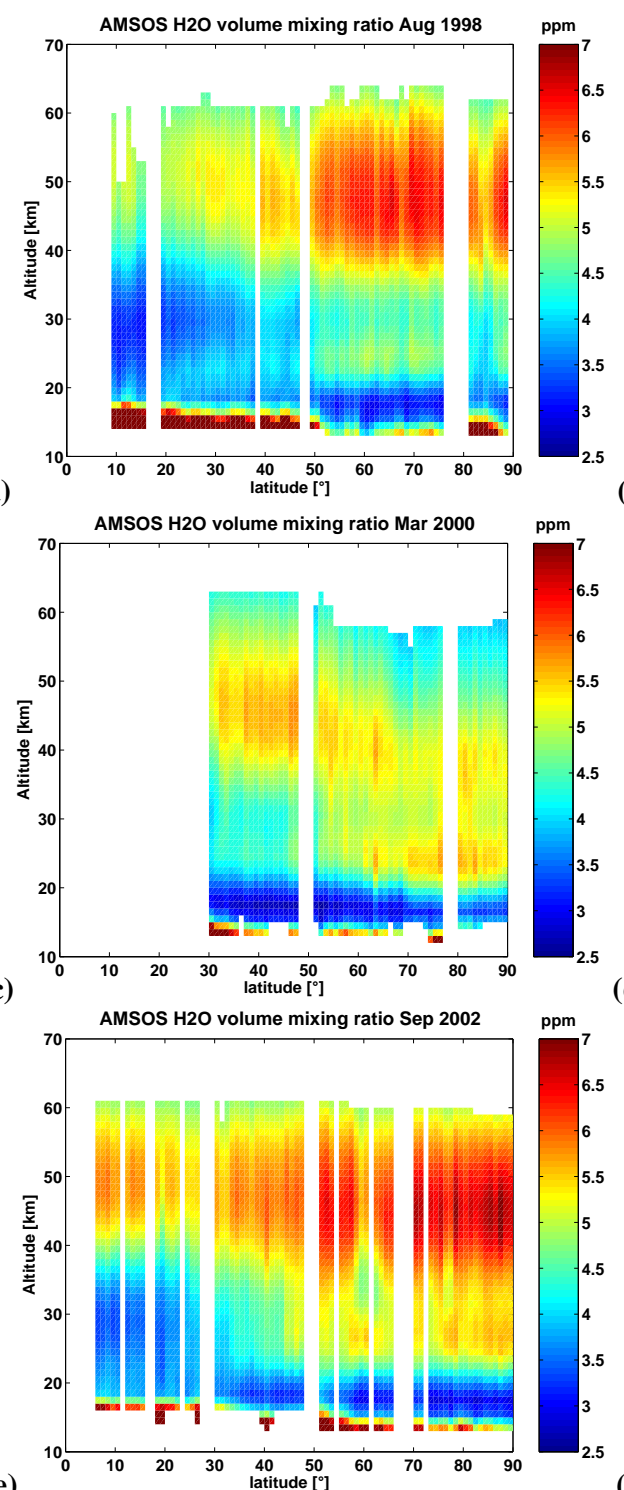

(e)

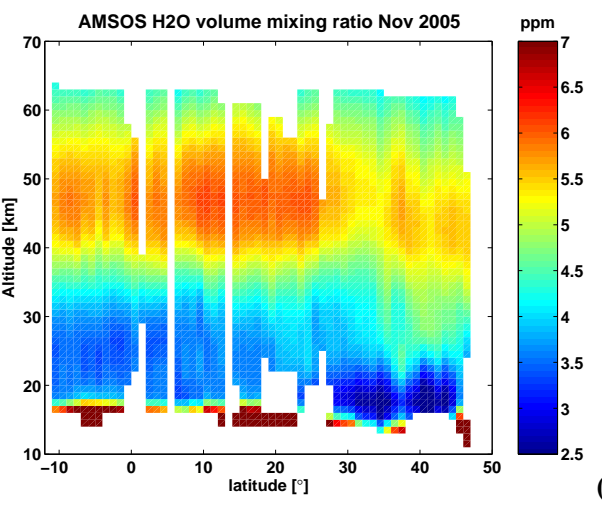

(b)
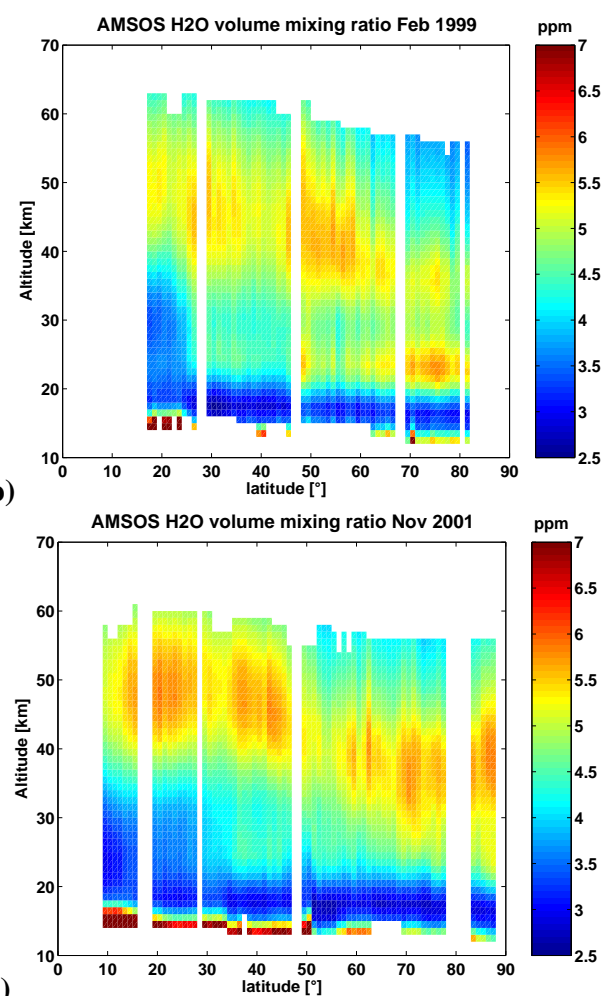

(d)

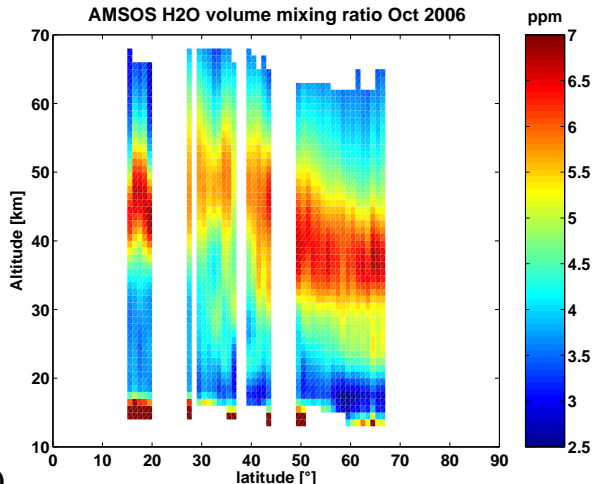

(f)

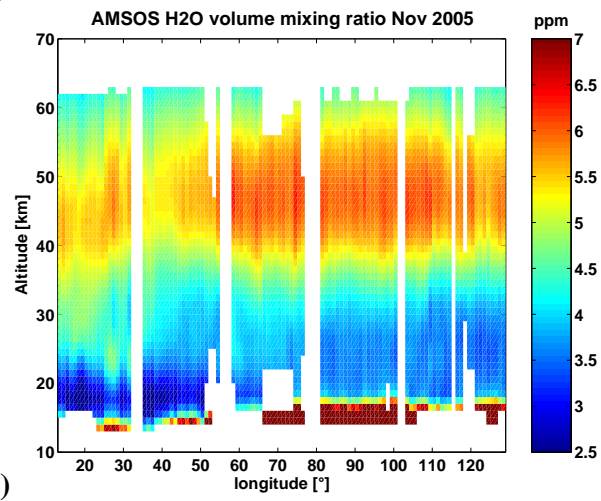

Fig. 4. The AMSOS dataset. Each plot (a)-(f) is devoted to the AMSOS missions 1-5 and 9 from Western Africa to the North pole in the different seasons spring and autumn and contains a graph with the measured vertical water vapour distributions plotted versus latitude. Graphs (g) and (h) are both for mission 8 from Europe to Australia once plotted versus latitude and once versus longitude. Only data with measurement responses larger than $50 \%$ has been included. Gaps are due to bad quality based on instrumental problems or due to measurements of ozone at $176 \mathrm{GHz}$. Profiles are averaged to $1^{\circ}$ in latitude respectively $1^{\circ}$ in longitude. 

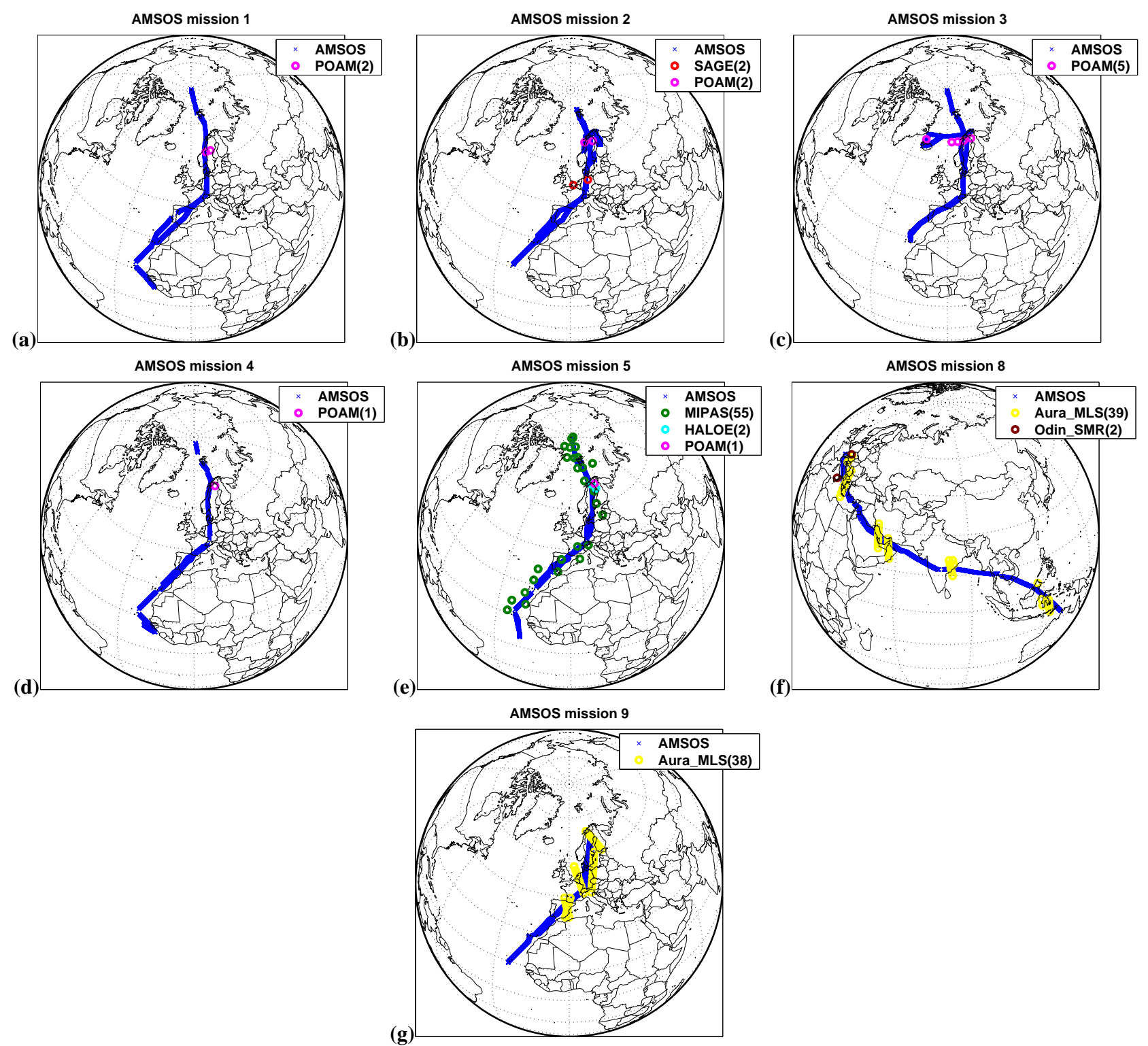

Fig. 5. AMSOS campaigns numbered by a mission identifier and collocations with satellite experiments for all flight campaigns. Each circle represents a collocation matching a criteria in space and time being within a $500 \mathrm{~km}$ radius and $10 \mathrm{~h}$ time window. The blue line represents the AMSOS flight track. The number in the legend represents the total number of collocations for that mission.

\subsection{AMSOS campaigns and dataset}

The here presented AMSOS dataset contains 4100 profiles presented in Fig. 4 from flight campaigns or missions between 1998 and 2006 as overviewed in Table 1 and Fig. 5. The instrument participated often as a part of international campaigns during this period. In most cases the flight route was planned to cover as many latitudes as possible between the equator and the north pole. The AMSOS flight track is indicated in blue for each mission in Fig. 5 where every plot is dedicated to one campaign. During participation in the SCOUT-O3 Darwin campaign in 2005 our track was in east-west direction including an overpass of the equator (see Fig. 5f).

Every flight mission presented in Fig. 4 by altitude latitude plots shows a very dry stratosphere with no more than $4 \mathrm{ppm}$ volume mixing ratio over the tropics up to $40 \mathrm{~km}$. In the mid-latitudes and polar region values of $5 \mathrm{ppm}$ are reached down to $20 \mathrm{~km}$. In the upper stratosphere the increase of water vapour generated by methane oxidation resulted in measurements at $50 \mathrm{~km}$ of up to $7 \mathrm{ppm}$. Above this height we observed decreasing water vapour induced by photolysis. In 
the November and February/March missions numbered 2, 3, 4 and 9 (see Fig. 4b, c, d and f) the water vapour maximum subsided to a level of $35 \mathrm{~km}$ above the Arctic. In the Tropics the tropopause extends to higher altitudes than in arctical regions. This effect can also be seen in the water vapour distribution. For example in Fig. 4e the high values at the bottom of the plot in red color extend to $17 \mathrm{~km}$ in the tropics and $13 \mathrm{~km}$ in the Arctic. For additional dynamical discussions see (Feist et al., 2007).

\section{AMSOS validation}

\subsection{Comparison technique}

When comparing data from two remote sensing instruments their vertical resolution has to be considered. Let us assume the instrument to compare with has a higher resolution. Applying the averaging kernels A of AMSOS according to Eq. (4) reduces its vertical resolution to the resolution of the lower resolved profile and smoothes out fine structures.

$x_{\mathrm{LR}}=x_{a}+\mathbf{A}\left(x_{\mathrm{HR}}-x_{a}\right)$

where $x_{\mathrm{HR}}$ is the high resolution and $x_{\mathrm{LR}}$ its equivalent reduced resolution profile from the comparative instrument and $x_{a}$ the apriori profile of AMSOS. This is a technique already used for comparisons between low and high resolution remote sounders by (Connor et al., 1995) and (Tsou et al., 1995).

In our case it was necessary to do a small modification due to the character of the water vapour profile and our possibility to measure in the upper troposphere. Below the hygropause water vapour increases exponentially. The term $\left(x_{\mathrm{HR}}-x_{a}\right)$ in (4) can become very large for different hygropause levels in $x_{\mathrm{HR}}$ and $x_{a}$. An averaging kernel function corresponding to a certain altitude level is minimal but not necessarily zero below the hygropause level as shown in Fig. 6 and consequently contribute significantly to the values of the smoothed profile in the upper stratosphere. Since our apriori profile is global and the altitude level of the hygropause changes with latitude this effect is encountered quite often. To get rid of this, we must apply the averaging kernels from hygropause level upwards, and lower down we take the direct difference of the profiles

$\begin{array}{ll}\Delta x=\frac{\hat{x}-x_{\mathrm{LR}}}{x_{\mathrm{LR}}} & \text { (above hygropause) } \\ \Delta x=\frac{\hat{x}-x_{\mathrm{HR}}}{x_{\mathrm{HR}}} & \text { (below hygropause) }\end{array}$

with $\hat{x}$ the retrieved AMSOS profile and $x_{\mathrm{LR}}, x_{\mathrm{HR}}$ the reduced resolution respectively original instrument profile.

This approach is used to compare the AMSOS measurements with the higher resolved limb sounding profiles from

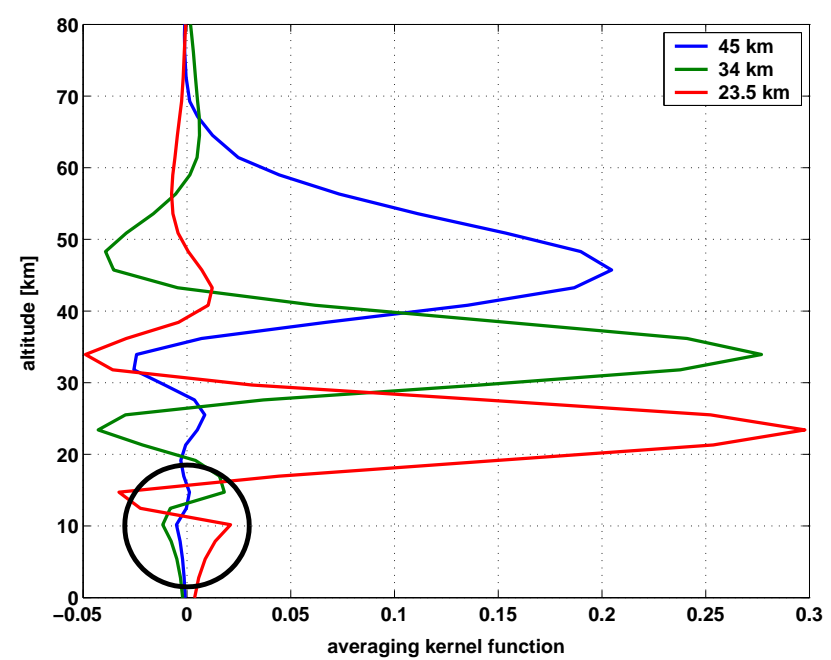

Fig. 6. Averaging kernel functions for different altitude levels. In the tropospheric part, marked by the black circle, they are not zero. Due to the strong tropospheric gradient the contribution from this part can be enormous when applying the averaging kernel functions to another profile for a comparison as described in Sect. 3.1.

satellite observations. In case of the comparison to the microwave ground-station MIAWARA we do not have to apply the averaging kernels because they already have similar vertical resolutions. For the comparisons to the in-situ instruments FISH and FLASH we picked the AMSOS value out on the corresponding altitude level. Concerning the differential absorption lidar we plotted the independent AMSOS and DIAL profiles in the overlap region in the UTLS. Independent in terms of that the DIAL profile was not used as apriori information in the AMSOS retrieval as better knowledge of the tropospheric water vapour distribution like in (Gerber et al., 2004).

\subsection{Comparisons with other instruments}

For an ideal validation study instruments measuring water vapour at almost the same place at the same time are needed. By flying directly over a ground-based station the constraint of place and time can be satisfied easily, as well as for the case of flying in parallel with another aircraft. In case of crossing the footprint of a satellite-based instrument a certain space and time frame has to be selected as the satellite and aircraft paths are not crossing at the same time or only nearby.

Comparative satellite experiments were the SPOT4/POAM-III (data downloaded from ftp: //poamb.nrl.navy.mil/pub/poam3/), ERBS/SAGE-II (data downloaded from http://badc.nerc.ac.uk/data/sage2/), UARS/HALOE (data downloaded from http://haloedata. larc.nasa.gov/), AURA/MLS (data downloaded from http://daac.gsfc.nasa.gov/Aura/MLS/), ENVISAT/MIPAS 
Table 1. Overview of the AMSOS flight campaigns from 1998-2006 with retrieved water vapour profiles.

\begin{tabular}{llrrrl}
\hline Mission & Date & Number of profiles & minimum latitude & maximum latitude & Campaign name \\
\hline 1 & $1998-08-24-1998-08-28$ & 576 & 8.8 & 88.1 & WAVE \\
2 & $1999-02-05-1999-02-12$ & 511 & 17.2 & 80.6 & THESEO 1999 \\
3 & $2000-03-08-2000-03-14$ & 621 & 29.7 & 89.6 & THESEO 2000/SOLVE \\
4 & $2001-11-09-2001-11-13$ & 759 & 9.4 & 86.6 & SPURT 2001 \\
5 & $2002-09-16-2002-09-20$ & 569 & 6.1 & 89.7 & \\
8 & $2005-11-04-2005-11-16$ & 838 & -10.8 & 45.7 & SCOUT-O3 \\
9 & $2006-10-30-2006-11-03$ & 226 & 15.4 & 65.5 & \\
\hline
\end{tabular}

Table 2. The set of instruments to which AMSOS was compared cover the whole electromagnetic spectrum from the UV to microwave by using different observation techniques like star occultation, limb sounding, ground-based measurements, lidar and in-situ observations. (Abbreviations: $\mathrm{RS}=$ Remote Sensing, $\mathrm{SO}=$ Star Occultation).

\begin{tabular}{|c|c|c|c|c|c|}
\hline Experiment & Platform & Technique & wavelength & data version & Reference \\
\hline POAM III & SPOT4 & $\mathrm{RS}, \mathrm{SO}, \operatorname{limb}$ & $385-1020 \mathrm{~nm}$ & V4 & (Nedoluha et al., 2002) \\
\hline SAGE II & ERBS & $\mathrm{RS}, \mathrm{SO}, \operatorname{limb}$ & $385-1020 \mathrm{~nm}$ & V6.2 & (Rind et al., 1993) \\
\hline HALOE & UARS & $\mathrm{RS}, \mathrm{SO}, \mathrm{limb}$ & $2.45-10.04 \mu \mathrm{m}$ & V19 & (Harries et al., 1996) \\
\hline MIPAS & ENVISAT & RS, limb & $4.15-14.6 \mu \mathrm{m}$ & $\begin{array}{l}\text { V3O_H2O_11 (IMK retrieval) } \\
\text { V4.62 (ESA retrieval) }\end{array}$ & $\begin{array}{l}\text { (Milz et al., 2005) } \\
\text { (Raspollini et al., 2006) }\end{array}$ \\
\hline SMR & Odin & $\mathrm{RS}$, limb & $488.9 \mathrm{GHz}$ & $\mathrm{V} 2.1$ & (Urban et al., 2007) \\
\hline MLS & AURA & $\mathrm{RS}, \operatorname{limb}$ & $183 \mathrm{GHz}$ & V1.5 & (Schoeberl et al., 2006) \\
\hline MIAWARA & Groundbased & RS, uplooking & $22 \mathrm{GHz}$ & 7 & (Deuber et al., 2005) \\
\hline DIAL & Falcon 20 (DLR) & RS, Lidar & $935 \mathrm{~nm}$ & & (Ehret et al., 1999) \\
\hline FISH & Geophysica M55 & In-situ & $121.6 \mathrm{~nm}$ & & (Zöger et al., 1999) \\
\hline FLASH & Geophysica M55 & In-situ & $121.6 \mathrm{~nm}$ & & (Sitnikov et al., 2007) \\
\hline
\end{tabular}

and Odin/SMR. In case of the MIPAS instrument the comparison was available using two different datasets from the European Space Agency (ESA) and the Institut für Meteorologie und Klimaforschung (IMK), Karlsruhe, Germany. This set of satellite experiments observing at different times makes the AMSOS instrument also useful for cross-validation studies by the technique given in (Hocke et al., 2006).

During the transfer flight of the SCOUT-O3 Darwin campaign, the Learjet has flown in parallel with the two aircraft, DLR Falcon 20 and the Russian Geophysica M55. Onboard the Falcon a Differential Absorption Lidar (DIAL) (Ehret et al., 1999) system was operated to measure the water vapour above the aircraft up to an altitude of about $17 \mathrm{~km}$. This gave an overlap region with the AMSOS profile in the upper troposphere letting us combine the water vapour profiles from two different systems. Finally, we compared our data with the instruments FISH and FLASH, which both use the Lyman- $\alpha$ line in the UV and perform in-situ measurements from the Geophysica aircraft.

An overview of all the instruments is given in Table 2. The whole set of instruments used for comparison include different remote sensing and in-situ techniques, passive and active methods, occultation, limb and up-looking, ground-based, airborne and satellite borne, and cover the electromagnetic spectrum from the ultraviolet to the microwave region.

\subsection{Validation with observations from satellites}

For the purpose of validation at all altitudes we compared the dataset to the six satellite experiments mentioned in Sect. 3.2. Figure 5 shows all the collocation pairs with satellite sensors for all AMSOS missions. During each flight mission we can find at least one collocation of an AMSOS profile and a satellite experiment within a radius of $500 \mathrm{~km}$ and a time difference of $10 \mathrm{~h}$. We are aware that this criteria can cause problems in the presence of the vortex edge with strong PV gradients. Nevertheless if we use a more stringent criteria the number of collocations would decrease rapidly. We found about 10 matching profiles in the first four AMSOS missions with SPOT4/POAM-III and 2 with ERBS/SAGE-II. These two satellite experiments are solar occultation instruments and thus only performed measurements during sunrise and sunset while the AMSOS instrument was flying mostly during daytime. With the UARS/HALOE instrument which also accomplished solar occultation measurements only two 
(a)
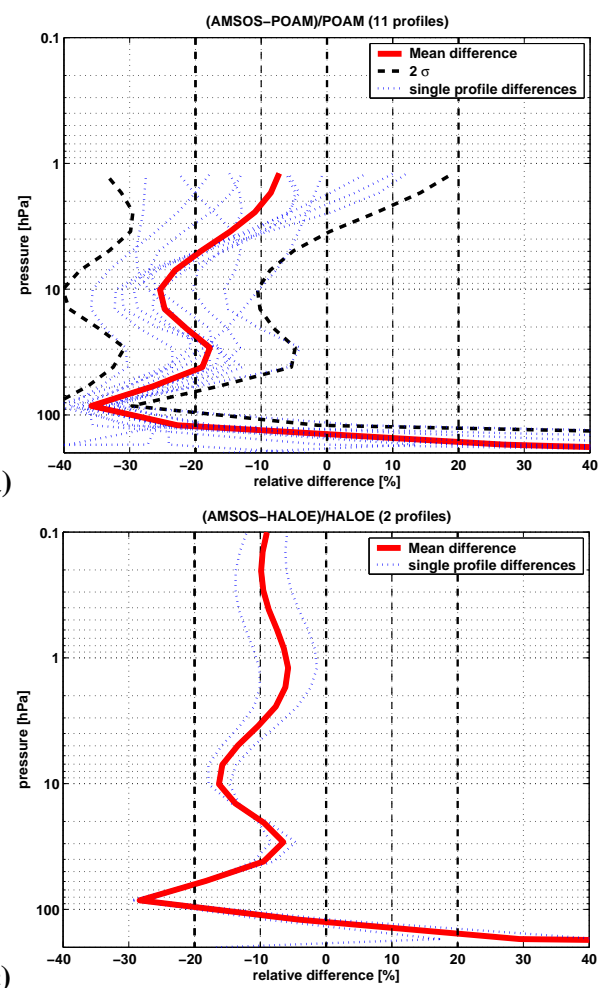

(c)

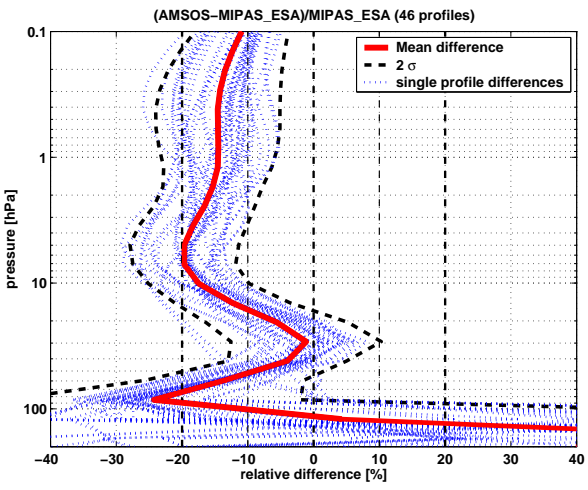

\section{(e)}

(b)

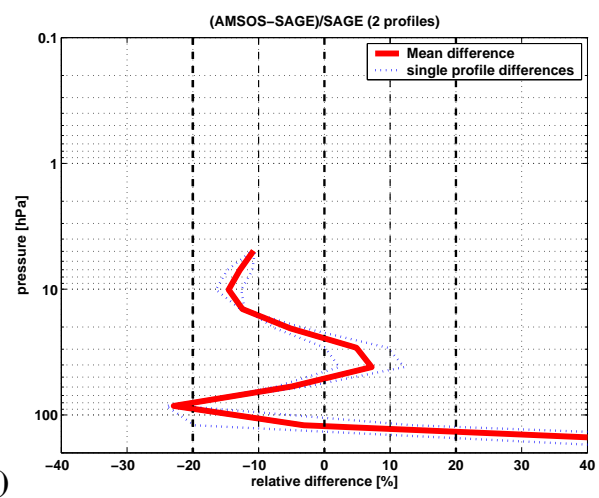

(d)
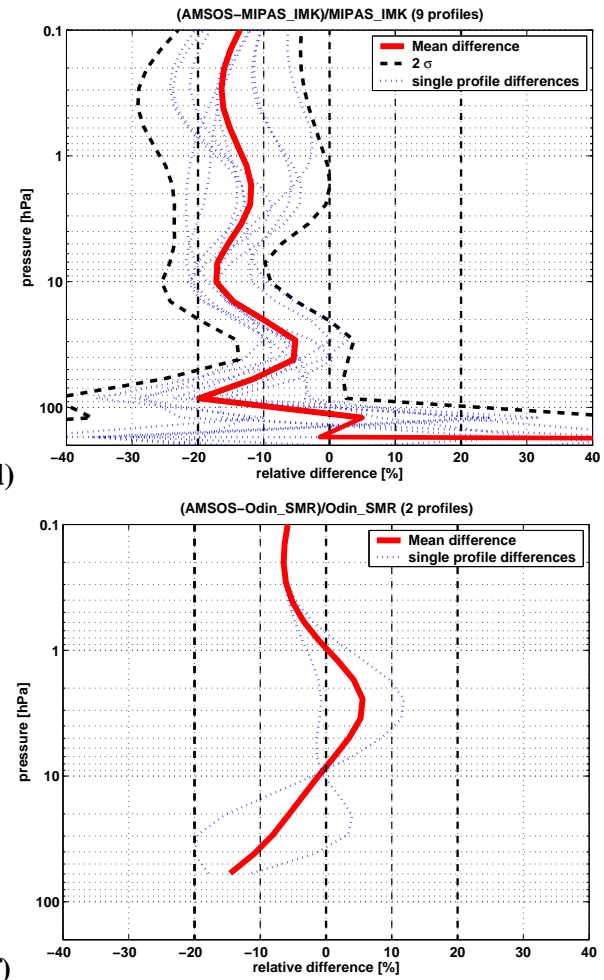

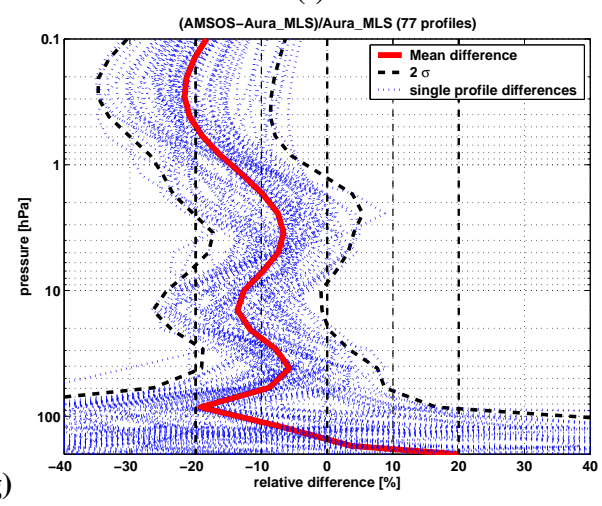

Fig. 7. Comparison of AMSOS with passive satellite remote sensing instruments (a)-(g). The satellite profiles were convolved with the averaging kernels of AMSOS as described in Sect. 3.1 to give them both equal vertical resolution. The thick red line shows the mean difference profile of all the blue dotted single differences of each collocation. Positive differences means that AMSOS is wetter than the independent data. Clearly visible in the plots (a)-(g) is the dry bias of AMSOS up to $-20 \%$. 


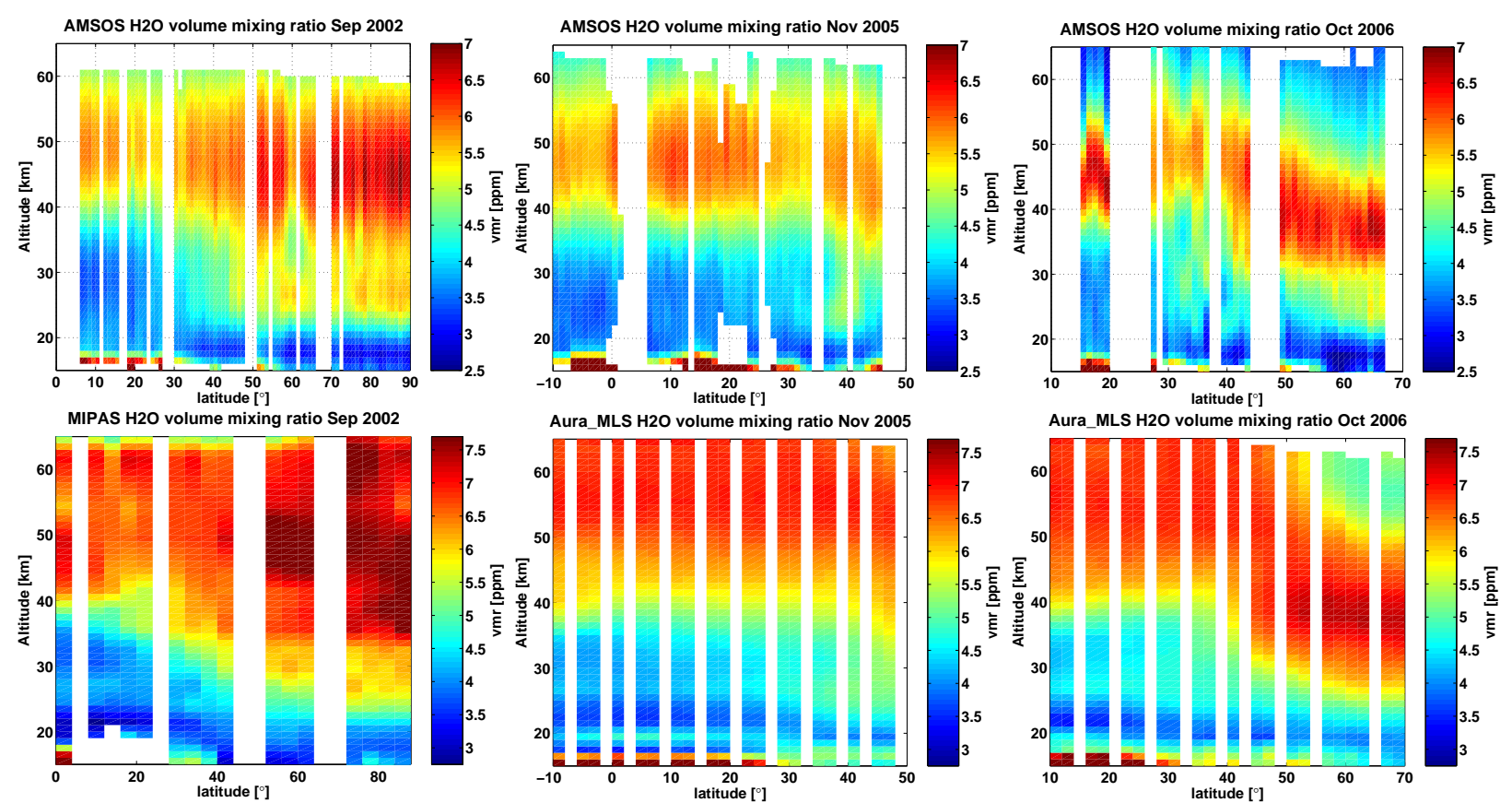

Fig. 8. Comparison of the latitudinal variations between AMSOS and ENVISAT/MIPAS respectively AURA/MLS for mission 5, 8 and 9. For better visuality the color code of the satellite plots was adapted accounting for a $10 \%$ dry bias of the AMSOS instrument.

collocations were found in mission 5. In the same mission there are more than forty coinciding measurements with ENVISAT/MIPAS which is a full-time measuring instrument. In the last two AMSOS missions several track crossings with the AURA satellite resulted in more than 75 collocation pairs with the MLS instrument.

The comparison is done over the altitude region where the satellite profile and the AMSOS profile overlap or where the measurement response is larger than 50\%. Profile differences were plotted in relative units according to

$\Delta \mathrm{VMR}[\%]=\frac{\mathrm{VMR}_{\mathrm{AMSOS}}-\mathrm{VMR}_{\text {Instrument }}}{\mathrm{VMR}_{\text {Instrument }}}$.

In Fig. 7 the thick red line is the mean relative difference of all the single difference profiles in dotted blue. The offset is negative when AMSOS measures drier values and positive when AMSOS has a wet bias.

The comparison to the POAM-III instrument (Fig. 7a) shows a relative difference of $-35 \%$ at $90 \mathrm{hPa}$ and then decreases below to $-10 \%$ at $1 \mathrm{hPa}$ with respect to AMSOS.

SAGE-II (Fig. 7b) shows a bias of $-22 \%$ at $90 \mathrm{hPa}$ which turns to positive values in the lower stratosphere before the mean difference is stabilized at $-12 \%$ between 10 and $5 \mathrm{hPa}$. Also HALOE (Fig. 7c) shows a $-29 \%$ offset at the $90 \mathrm{hPa}$ level and a quasi constant offset of $-10 \%$ up to $0.1 \mathrm{hPa}$. Both HALOE and SAGE-II with only two collocations did not issue additional statistical information but nevertheless they show the same typical features in the mean difference profile as the others.
In case of the MIPAS instrument we compared to two different independent retrievals. On the one hand the IMK (Fig. 7d) retrieval and on the other hand (Fig. 7e) the ESA operational retrieval. Collocations with IMK profiles do not cover latitudes northerly than $66^{\circ} \mathrm{N}$. Both profile sets show a similar behaviour. Again the $90 \mathrm{hPa}$ level is offsetted by $-20 \%$ (IMK) to $-25 \%$ (ESA). At $30 \mathrm{hPa}$ it changes to $-5 \%$ (IMK) and no offset (ESA). Between 10 and $0.1 \mathrm{hPa}$ the offset is $-15 \%$ in the mean for both. In case of the ESA retrieval it is slightly decreasing in this altitude range.

The two profiles of the Odin/SMR instrument compare well with the AMSOS instrument. The error amounts between $-15 \%$ and $+5 \%$ in the altitude range of 60 to $0.1 \mathrm{hPa}$. It is slightly positive between 1 and $10 \mathrm{hPa}$. But also here the number of collocations is too low to make a statistical conclusion.

The AURA/MLS instrument using the same observation frequency as AMSOS also shows a clearly offset of $-20 \%$ at the $90 \mathrm{hPa}$ level. Throughout the stratosphere it is similar to the HALOE comparison at $-10 \%$ and increasing to $-20 \%$ in the lower mesosphere between 0.1 and $1 \mathrm{hPa}$. This maybe due to increasing apriori contribution in the AMSOS profiles at these altitudes. 

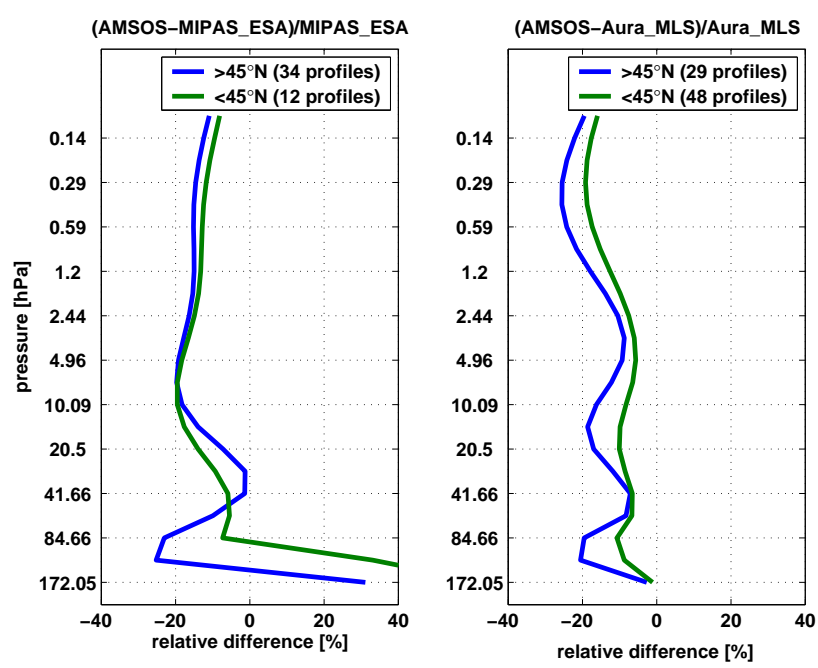

Fig. 9. Mean profile differences between AMSOS and ENVISAT/MIPAS (ESA retrieval) on the left and AMSOS and AURA/MLS on the right for polar in blue and tropical latitudes in green. Positive differences means that AMSOS is wetter. The difference profiles are dependent on the latitude. Polar profiles show a characteristic peak in the UTLS region at $90 \mathrm{hPa}$.

\subsection{Comparison of latitudinal variations of AMSOS and satellites}

Figure 8 shows latitudinal avarages of the AMSOS dataset compared to the MIPAS dataset ESA retrieval for mission 5 (September 2002) and to the AURA/MLS dataset for mission 8 (November 2005) and mission 9 (late October 2006). The dry bias of the AMSOS instrument is accounted by scaling the color code in the satellite datasets by $10 \%$. The latitudinal variations of AMSOS are visible and are similar to the satellite datasets. In mission 5 the AMSOS dataset changes quite fast between $30^{\circ} \mathrm{N}$ and $50^{\circ} \mathrm{N}$ between the polar and tropical region, seen in the values of $5 \mathrm{ppm}$ extending down to $25 \mathrm{~km}$ respectively $40 \mathrm{~km}$, while in the MIPAS data this change is continously between $20^{\circ} \mathrm{N}$ and $60^{\circ} \mathrm{N}$. At $25^{\circ} \mathrm{N}$ in the altitude of $42 \mathrm{~km}$ both datasets see less water vapour than at latitudes beside. Mission 8 was a flight campaign from the mid-latitudes to the tropics with less expected latitudinal variations than the other examples. Nevertheless in the mid-latitudinal part both captured an area of enhanced water vapour (yellow colored) at $25 \mathrm{~km}$ altitude. In the tropics the MLS data show another enhanced water vapour layer at $20 \mathrm{~km}$ (cyan colored) which is not seen in the AMSOS data. The vertical extension of this layer is too small and the enhancement in water vapour amounts is not enough to be observed by AMSOS due to the limited altitude resolution. In mission 9, which shows again an Arctic-to-tropics cross section, both datasets provide a rapid change between typical arctic and tropical profiles between $40^{\circ} \mathrm{N}$ and $45^{\circ} \mathrm{N}$ seen
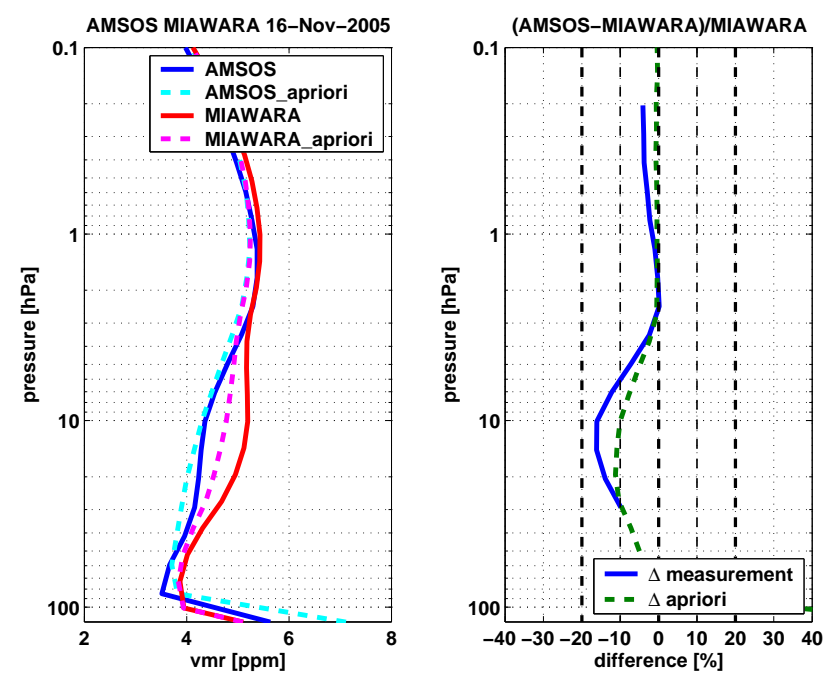

Fig. 10. Comparison to the ground-station MIAWARA situated in Bern in November 2005. On the left side the AMSOS profile, the MIAWARA profile and their apriori profiles. On the right side the relative difference shows an agreement of 0 to $-17 \%$. Positive differences means that AMSOS is wetter than MIAWARA. The shape of the difference profile follows the shape of the difference in the apriori profiles.

in the change in altitude of the stratospheric water vapour maximum. Also a very dry mesospheric part in the Arctic is seen in both.

\subsection{Latitude dependence}

As seen in Sect. 3.3 all the mean difference profiles of the comparisons with satellite data show a negative peak at the $90 \mathrm{hPa}$ level. It seems to be a character of the AMSOS profile to be very dry around the hygropause. When analyzing the locations of the collocations most of them originate in the mid-latitudinal to polar region. For the collocations between AMSOS and AURA/MLS, or AMSOS and ENVISAT/MIPAS, both of which cover subtropical and more northerly latitudes, we separated the profile comparisons in two geographical regions, the first from $90^{\circ} \mathrm{N}$ to $45^{\circ} \mathrm{N}$ and the second from $45^{\circ} \mathrm{N}$ to $0^{\circ} \mathrm{N}$. As shown in Fig. 9 the mean difference profile is dependent on latitude. The characteristic peak is visible only in the profiles north of $45^{\circ} \mathrm{N}$. In case of the MIPAS instrument the two mean difference profiles differ only in the UTLS region up to $10 \mathrm{hPa}$ while the two MLS regional mean difference profiles are slightly offset by less than $10 \%$ over the whole altitude range.

The origin of this peak at $90 \mathrm{hPa}$ can be explained by a shift in altitude of the hygropause in the AMSOS profiles. The reason why this appears only in the polar profiles is due to the apriori profile of AMSOS and its covariance matrix. In polar regions the hygropause is located at a lower altitude 

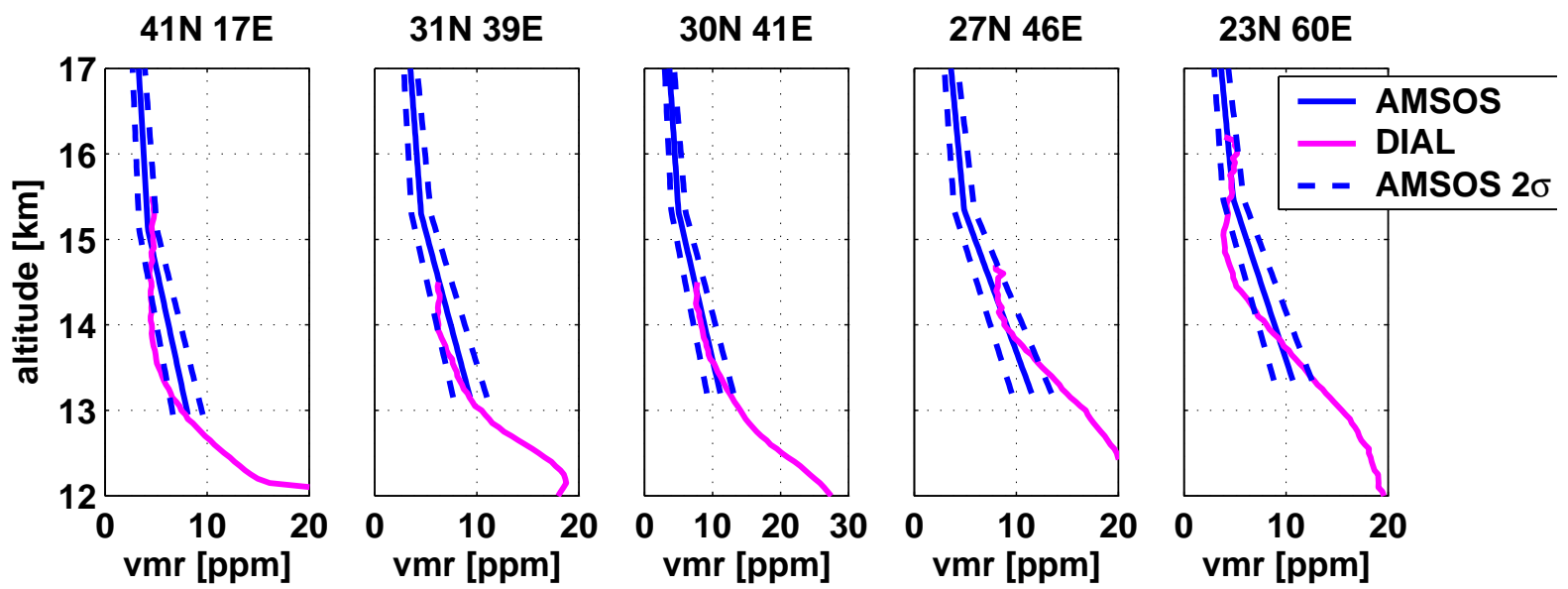

Fig. 11. Combination of AMSOS profiles with DIAL profiles from DLR lidar onboard a Falcon during the transfer flight of the SCOUT-O3 campaign 2005. The top of the lidar profile in magenta matches within the $2 \sigma$ error at the bottom of the AMSOS profile in blue.

level than in tropical or mid-latitudinal regions. The location of the hygropause in the used apriori profile is at $90 \mathrm{hPa}$ and represents more a sub-tropical case. The constraint of the apriori profile by the covariance matrix $\mathbf{S}_{x}$ in the upper troposphere retained the hygropause of the AMSOS profiles on a certain altitude level. This leads to too high AMSOS values and a positive difference profile below $120 \mathrm{hPa}$. The retrieval algorithm compensates this by too low values above and lead to this negative peak in the difference profile at $90 \mathrm{hPa}$. The positive peak at $30 \mathrm{hPa}$ is another recompensation. The oscillating effect disappears in tropical and mid-latitudinal regions.

By using different apriori profiles, one for each typical regions, arctic, mid-latitude and tropical, the retrieval would be improved around the hygropause. Since the retrieval is largely dependent on the apriori information, the use of different apriori profiles would make our whole dataset inconsistent and would lead to a split in different subdatasets each for one of the apriori profiles. To avoid this we decided to use only one apriori profile. Tests with a polar apriori profile have shown to have the hygropause located at a lower altitude level and thus might improve the retrieval but an oscillating structure still remains in the difference profile when comparing to satellites.

\subsection{Validation with the ground-station MIAWARA}

There was one coinciding measurement with the groundbased microwave radiometer MIAWARA (Deuber et al., 2005 ) in Bern, Switzerland on 16th November 2005. The left hand side of Fig. 10 shows both the AMSOS and the MIAWARA profile and their apriori profiles used for the retrievals. Taking the relative difference (Fig. 10 right) resulted in an agreement of -17 to $0 \%$ at pressure levels between 30 and $0.2 \mathrm{hPa}$ where the measurement response of both instru- ments is larger than 0.5. The shape of the difference profile follows the shape of the difference in the apriori profiles. Thus the difference of $-17 \%$ in the altitude of $11 \mathrm{hPa}$ can be explained by the difference of $10 \%$ in the apriori profiles.

\subsection{Validation of AMSOS upper tropospheric humidity with lidar profiles}

In each viewgraph of Fig. 11 we plotted the corresponding profiles from the two different measurement techniques lidar and microwave covering different altitude regions. Profiles are averaged over 1 degree in longitude. The lidar profile from the DIAL instrument reaches the upper troposphere where the AMSOS instrument starts to be sensitive to water vapour. 4 cloudless cases from the mid-latitudes to the subtropics are presented here. The lidar profiles match into the $2 \sigma$ error of the AMSOS profile. The different vertical gradients in the profiles is clearly visible in the first case of Fig. 11 $(41 \mathrm{~N}, 17 \mathrm{E})$ originate in the limited vertical resolution of the microwave instrument.

\subsection{Validation with in-situ hygrometers FISH and FLASH}

On the transfer flight of the SCOUT-O3 Darwin campaign we had the possibility to fly in parallel with the Lyman- $\alpha$ hygrometers FISH and FLASH that were carried by the aircraft Geophysica-M55.

The measurements for this comparison were averaged to one degree in longitude along the flight track. There are no FLASH measurements available between $10^{\circ} \mathrm{E}$ to $50^{\circ} \mathrm{E}$. As shown in Fig. 12b aircraft Geophysica-M55 was flying above hygropause level and, except for the path between $110^{\circ}$ and $130^{\circ}$ longitude, the absolute values are similar and fit within the error bars of the AMSOS instrument (see Fig. 12a). In the last part the in-situ instruments are at the border of the 
(a)

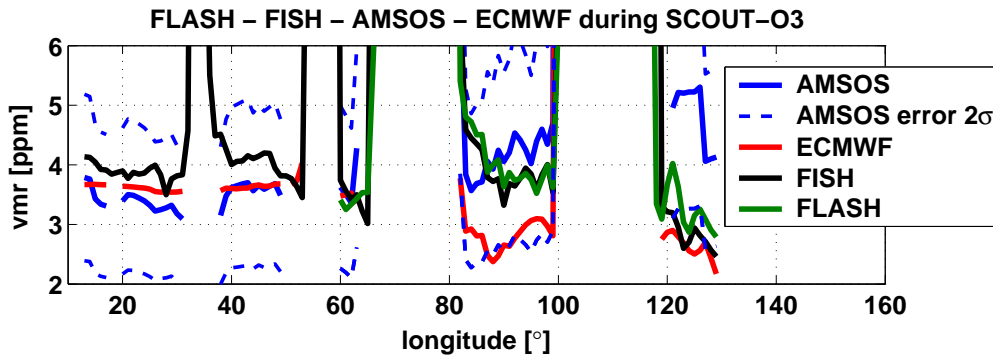

(b)

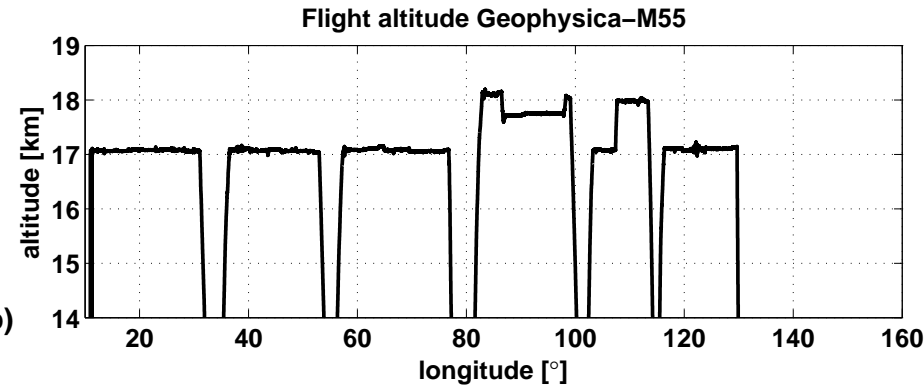

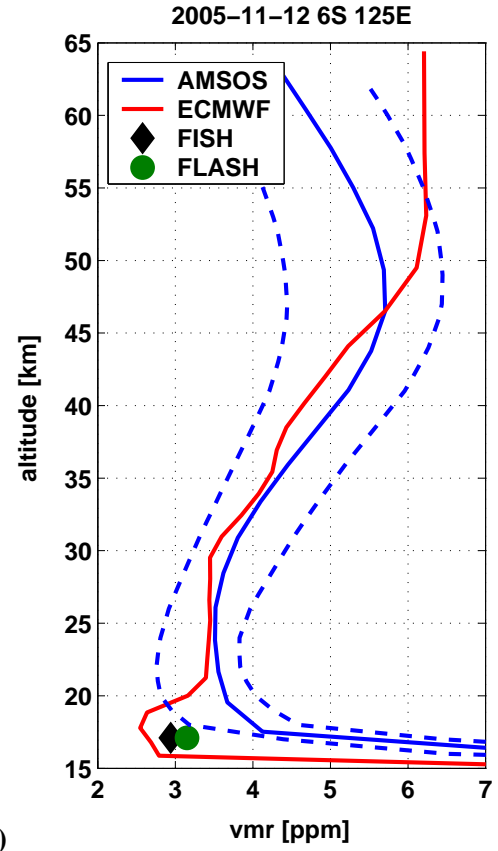

Fig. 12. Comparison of AMSOS profiles with in-situ measurements from FLASH and FISH sondes onboard aircraft Geophysica during SCOUT-O3 Darwin campaign. Plot (a) shows the measured volume mixing ratio of the instruments and modelled data from ECMWF at Geophysica-M55 flight altitude level in (b). The sharp jumps in vmr at $35^{\circ}, 60^{\circ}, 70^{\circ}, 80^{\circ}, 100^{\circ}$ and $120^{\circ}$ longitude are due to ascent and descent of the aircraft through the troposphere. The values match within the $2 \sigma$ error bars until $100^{\circ} \mathrm{E}$, then the in-situ instruments measured concentrations near the border of the error bars. Correlation coefficients for AMSOS and FLASH is 0.63 and AMSOS and FISH is 0.52. Plot c) shows a thin water vapour layer in the ECMWF profile which is not seen by the AMSOS profile. FISH and FLASH measurements were made within this layer and lead to the larger difference to AMSOS in the last part of the flight.

AMSOS $2 \sigma$ error. Looking more into detail of the path between $110^{\circ}$ and $130^{\circ}$ we can identify in the ECMWF profile in Fig. 12c a small very dry layer near the hygropause where Geophysica was located. Due to the limited altitude resolution AMSOS did not detect this feature of the water vapour profile. In general it is difficult to compare a point measurement with a smeared measurement with a much lower altitude resolution thus it does not make sense to give an absolute value for a certain difference. Nevertheless the in-situ hygrosondes fit within the AMSOS error bars. Correlation coefficients for AMSOS and FLASH is 0.63 and AMSOS and FISH is 0.52 .

\section{Conclusions}

The AMSOS water vapour dataset consists of more than 4000 profiles from the UTLS region up to the mesosphere covering all latitudes from tropical to polar regions with horizontal resolution of $57 \mathrm{~km}$. The airborne instrument was running for approximately one week each year between 1998 and 2006. The main features of the vertical water vapour distribution are clearly seen by the radiometer data despite the limited altitude resolution of $8-16 \mathrm{~km}$. The upper tropo- spheric part with the strong gradient in water vapour is visible as well as the water vapour maximum, which is the main feature in the stratosphere, as a footprint of methane oxidation and transport by the Brewer-Dobson circulation. The water vapour minimum, also known as the hygropause, is apparent over the tropics at a higher altitude level than over the Arctic. In the late winter missions of 1999 and 2000 and the late autumn missions of 2001 and 2006 with the presence of the polar vortex lower water vapour values were measured in the Arctic upper stratosphere compared to the late summer missions of 1998 and 2002. Due to the subsidence of air over the pole by the Brewer-Dobson circulation and on the other hand also as an effect of the polar vortex that builds a barrier for the transport of mid-latitudinal air masses towards the pole.

Validation of the whole dataset in the different years of measurements and over the whole geographical region was successfully done with a large set of different instrument types using different data collection methods and different data processing algorithms. Comparisons with satellite borne passive remote sensing instruments show a dry bias of the AMSOS instrument in the order of 0 to $-20 \%$. Beside a constant offset a bias dependency appears with latitude. A 
typical mean difference profile in the Arctic has a sharp peak at the $90 \mathrm{hPa}$ level while this does not appear in the tropical profiles as seen in the comparisons with MLS and MIPAS. Dispite the fact that there is not much statistical information the characteristic peak is also visible in comparisons with HALOE, SAGE-II and POAM-III data which have collocations only in the Arctic. The global apriori of the AMSOS dataset and its covariance matrix constrain the tropospheric part too strongly which leads to a shift in altitude of the hygropause level for retrieved polar AMSOS profiles. Our apriori profile is representing more a subtropical, mid-latitudinal water vapour distribution than an Arctic. Since the retrieval is largely dependent on apriori information, the choice to use only one apriori was made to have a consistent dataset from the Tropics to the Pole based on the same apriori profile. Concerning the in-situ instruments FISH and FLASH during SCOUT-O3 campaign in 2005 they match within the AMSOS error bars for non special conditions as was the case for flightlegs 1-4. If the sondes are flying inside small fine water vapour structures such as during flightlegs 5 and 6 then AMSOS is not able to resolve this fine structure but the measurement points of the hygrometers are in the order of the $2 \sigma$ error bars. A matching of lidar profiles from DIAL and the AMSOS microwave profiles in the upper troposphere for non cloudy situations was also found during SCOUT-O3. Thus a combination of a lidar and a microwave radiometer allowed to measure water vapour from the troposphere up to the mesosphere during the SCOUT-O3 campaign.

Mesospheric water vapour profiles up to an altitude of $75 \mathrm{~km}$ retrieved from a different spectrometer will be added to the dataset later.

Acknowledgement. Stefan C. Müller's work was supported by the Swiss National Science Foundation under grant 200020-115882. We would like to thank the Swiss Air Force for providing the aircraft and especially the aircraft pilots for their excellent support during the flight campaigns. We thank also the ECMWF, HALOE, ESA, AURA, POAM and SAGE teams for providing their data.

Edited by: Rob MacKenzie

\section{References}

Buehler, S. A., Eriksson, P., Kuhn, T., von Engeln, A., and Verdes, C.: ARTS, the Atmospheric Radiative Transfer Simulator, J. Quant. Spectrosc. Radiat. Transfer, 91, 65-93, doi:10.1016/j. jqsrt.2004.05.051, 2005.

Chiou, E., McCormick, M., and Chu, W.: Global water vapor distributions in the stratosphere and upper troposphere derived from 5.5 years of SAGE II observations (1986-1991), J. Geophys. Res., 102, 105-118, doi:10.1029/97JD01371, 1997.

Connor, B. J., Parrish, A., Tsou, J.-J., and McCormick, M. P.: Error analysis for the ground-based microwave ozone measurements during STOIC, J. Geophys. Res., 100, 9283-9291, doi:10.1029/ 94JD00413, 1995.
Deuber, B., Kämpfer, N., and Feist, D. G.: A new 22-GHz Radiometer for Middle Atmospheric Water Vapour Profile Measurements, IEEE Transactions on Geoscience and Remote Sensing, 42, 974-984, doi:10.1109/TGRS.2004.825581, 2004.

Deuber, B., Haefele, A., Feist, D. G., Martin, L., Kampfer, N., Nedoluha, G. E., Yushkov, V., Khaykin, S., Kivi, R., and Vomel, H.: Middle Atmospheric Water Vapour Radiometer - MIAWARA: Validation and first results of the LAUTLOS / WAVVAP campaign, J. Geophys. Res., 110, D13306, doi:10.1029/ 2004JD005543, 2005.

Ehret, G., Hoinka, K. P., Stein, J., Fix, A., Kiemle, C., and Poberaj, G.: Low stratospheric water vapor measured by an airborne DIAL, J. Geophys. Res., 104, 351-359, doi:10.1029/ 1999JD900959, 1999.

Eriksson, P., Jimenez, C., and Buehler, S. A.: Qpack, a general tool for instrument simulation and retrieval work, J. Quant. Spectrosc. Radiat. Transfer, 91, 47-64, doi:10.1016/j.jqsrt.2004.05. 050, 2005.

Feist, D. G., Geer, A. J., Müller, S., and Kämpfer, N.: Middle atmosphere water vapour and dynamical features in aircraft measurements and ECMWF analyses, Atmos. Chem. Phys., 7, 52915307, 2007, http://www.atmos-chem-phys.net/7/5291/2007/.

Fischer, H., Birk, M., Blom, C., Carli, B., Carlotti, M., von Clarmann, T., Delbouille, L., Dudhia, A., Ehhalt, D., Endemann, M., Flaud, J. M., Gessner, R., Kleinert, A., Koopmann, R., Langen, J., López-Puertas, M., Mosner, P., Nett, H., Oelhaf, H., Perron, G., Remedios, J., Ridolfi, M., Stiller, G., and Zander, R.: MIPAS: an instrument for atmospheric and climate research, Atmos. Chem. Phys., 8, 2151-2188, 2008,

http://www.atmos-chem-phys.net/8/2151/2008/.

Gerber, D., Balin, I., Feist, D. G., Kämpfer, N., Simeonov, V., Calpini, B., and van den Bergh, H.: Ground-based water vapour soundings by microwave radiometry and Raman lidar on Jungfraujoch (Swiss Alps), Atmos. Chem. Phys., 4, 2171-2179, 2004 , http://www.atmos-chem-phys.net/4/2171/2004/.

Harries, J., Russel III, J., Tuck, A., Gordley, L., Purcell, P., Stone, K., Bevilaqua, R., Gunson, M., Nedoluha, G., and Traub, W.: Validation of measurements of water vapor from the Halogen Occultation Experiment (HALOE), Journal of Geophysical Research, 101, 205-216, doi:10.1029/95JD02933, 1996.

Hocke, K., Haefele, A., Drian, C. L., Kämpfer, N., Ruffieux, D., von Clarmann, T., Milz, M., Steck, T., Froidevaux, L., Pumphrey, H. C., Jimenez, C., Walker, K. A., Bernath, P., Timofeyev, Y. M., and Polyakov, A. V.: Cross-validation of recent satellite and ground-based measurements of ozone and water vapor in the middle atmosphere, in: ESA Atmospheric Science Conference 2006, edited by: ESA, 2006.

Janssen, M. A.: Atmospheric remote sensing by microwave radiometry, Wiley Series in Remote Sensing, John Wiley \& Sons, Inc., New York, 1993.

Lahoz, W. A., Suttie, M. R., Froidevaux, L., Harwood, R. S., Lau, C. L., Lungu, T. A., Peckham, G. E., Pumphrey, H. C., Read, W. G., Shippony, Z., Suttie, R. A., Waters, J. W., Nedoluha, G. E., Oltmanns, S. J., Russell III, J. M., and Traub, W. A.: Validation of UARS microwave limb sounder $183 \mathrm{GHz} \mathrm{H}_{2} \mathrm{O}$ measurements, J. Geophys. Res., 101, 10 129-10 149, doi:10.1029/95JD01703, 1996. 
Lucke, R., Korwan, D., Bevilaqua, R., Hornstein, J., Shettle, E., Chen, D., Daehler, M., Lumpe, J., Fromm, M., Debrestian, D., Neff, B., Squire, M., König-Langlo, G., and Davies, J.: The Polar Ozone and Aerosol Measurement (POAM) III instrument and early validation results, J. Geophys. Res., 104, 785-799, doi: 10.1029/1999JD900235, 1999.

Milz, M., von Clarmann, T., Fischer, H., Glatthor, N., Grabowski, U., Höpfner, M., Kellmann, S., Kiefer, M., Linden, A., Tsidu, G. M., Steck, T., and Stiller, G. P.: Water vapor distributions measured with the Michelson Interferometer for Passive Atmospheric Sounding on board Envisat (MIPAS/Envisat), J. Geophys. Res., 110, D24307, doi:10.1029/2005JD005973, 2005.

Nedoluha, G. E., Bevilacqua, R. M., Gomez, R. M., Thacker, D. L., Waltman, W. B., and Pauls, T. A.: Ground-based measurements of water vapor in the middle atmosphere, J. Geophys. Res., 100, 2927-2939, doi:10.1029/96JD01741, 1995.

Nedoluha, G. E., Bevilaqua, R. M., Hoppel, K. W., Lumpe, J. D., and Smit, H.: Polar Ozone and Aerosol Measurement III measurements of water vapor in the upper troposphere and lowermost stratosphere, J. Geophys. Res., 107(D10), 4103, doi: 10.1029/2001JD000793, 2002.

Peter, R.: Stratospheric and mesospheric latitudinal water vapor distributions obtained by an airborne millimeter-wave spectrometer, J. Geophys. Res., 103, 16275-16290, doi:10.1029/98JD00968, 1998.

Raspollini, P., Belotti, C., Burgess, A., Carli, B., Carlotti, M., Ceccherini, S., Dinelli, B. M., Dudhia, A., Flaud, J.-M., Funke, B., Höpfner, M., López-Puertas, M., Payne, V., Piccolo, C., Remedios, J. J., Ridolfi, M., and Spang, R.: MIPAS level 2 operational analysis, Atmos. Chem. Phys., 6, 5605-5630, 2006,

http://www.atmos-chem-phys.net/6/5605/2006/.

Rees, D., Barnett, J. J., and Labitzke, K.: CIRA 1986, COSPAR International Reference Atmosphere Part I: Middle Atmosphere Models, 10, 1990.

Rind, D., Chiou, E., Larsen, J., Chu, W., McCormick, M., McMaster, L., Oltmans, S., and Lerner, J.: Overview of the Stratospheric Aerosol and Gas Experiment II water vapor observations: Method, validation, and data characteristics, J. Geophys. Res., 98, 4835-4856, doi:10.1029/92JD01174, 1993.

Rodgers, C. D.: Inverse Methods for Atmospheric Sounding: Theory and Practice, vol. 2 of Series on atmospheric, oceanic and planetary physics, World Scientific Publishing Co. Pte. Ltd., P O Box 128, Farrer Road, Singapore 912805, 2000.

Rothman, L. S., Rinsland, C. P., Goldman, A., Massie, S. T., Edwards, D. P., Flaud, J.-M., Perrin, A., Camy-Peyret, C., Dana, V., Mandin, J.-Y., Schroeder, J., McCann, A., Gamache, R. R., Wattson, B. B., Yoshino, K., Chance, K. V., Jucks, K. W., Brown, L. R., Nemtchinov, V., and Varanasi, P.: The HITRAN molecular spectroscopic database and HAWKS (HITRAN Atmospheric Workstation): 1996 edition, 60, 665-710, doi:10.1016/S0022-4073(98)00078-8, 1998.

Russell III, J. M., Gordley, L. L., Park, J. H., Drayson, S. R., Hesketh, W. D., Cicerone, R. J., Tuck, A. F., Frederick, J. E., Harries, J. E., and Crutzen, P. J.: The Halogen Occultation Experiment, 98, 10 777-10 797, doi:10.1029/2002JD002662, 1993.
Schoeberl, M. R., Douglass, A. R., Hilsenrath, E., Bhartia, P. K., Beer, R., Waters, J. W., Gunson, M. R., Froidevaux, L., Gille, J. C., Barnett, J. J., Levelt, P. F., and DeCola, P.: Overview of the EOS Aura Mission, IEEE Transactions on Geoscience and Remote Sensing, 44, 1066-1074, doi:10.1109/TGRS.2005.861950, 2006.

Siegenthaler, A., Lezeaux, O., Feist, D. G., and Kämpfer, N.: First water vapor measurements at $183 \mathrm{GHz}$ from the high alpine station Jungfraujoch, IEEE Transactions on Geoscience and Remote Sensing, 39, 2084-2086, doi:10.1109/36.951108, 2001.

Sitnikov, N., Yushkov, V., Afchine, A., Korshunov, L., Astakhov, V., Ulanovskii, A., Kraemer, M., Mangold, A., Schiller, C., Ravegnani, and F.: The FLASH instrument for water vapor measurements on board the high-altitude airplane, Instruments and Experimental Techniques, 50, 113-121, doi:10.1134/ S0020441207010174, 2007.

SPARC: SPARC Assessment of Upper Tropospheric and Stratospheric Water Vapour, 2000.

Tsou, J. J., Connor, B. J., Parrish, A., McDermid, I. S., and Chu, W. P.: Ground-based microwave monitoring of middle atmosphere ozone: Comparison to lidar and Stratospheric and Gas Experiment II satellite observations, J. Geophys. Res., 100, 3005 3016, doi:10.1029/94JD02947, 1995.

Urban, J., Lautie, N., Murtagh, D., Eriksson, P., Kasai, Y., Lossow, S., Dupuy, E., de La Noë, J., Frisk, U., Olberg, M., Flochmoën, E. L., and Ricaud, P.: Global observations of middle atmospheric water vapour by the Odin satellite: An overview, Planetary and Space Science, 55, 1093-1102, doi:10.1016/j.pss.2006.11.021, 2007.

US Committee on Extension to the Standard Atmosphere: US Standard Atmosphere, 1976, US Government Printing Office, Washington, D.C., USA, 1976.

Vasic, V., Feist, D. G., Müller, S., and Kämpfer, N.: An airborne radiometer for stratospheric water vapor measurements at 183 GHz, IEEE Transactions on Geoscience and Remote Sensing, 43, 1563-1570, doi:10.1109/TGRS.2005.846860, 2005.

Vömel, H., Yushkov, V., Khaykin, S., Korshunov, L., Kyrö, E., and Kivi, R.: Intercomparisons of Stratospheric Water Vapor Sensors: FLASH-B and NOAA/CMDL Frost-Point Hygrometer, J. Atmos. Oceanic Technol., 24, 941-952, doi:10.1175/ JTECH2007.1, 2007.

WMO: Scientific Assessment of Ozone Depletion: 2006, Global Ozone Research and Monitoring Project-Report No. 50, WMO, http://www.esrl.noaa.gov/csd/assessments/2006/, 2007.

Zöger, M., Afchine, A., Eicke, N., Gerhards, M.-T., Klein, E., McKenna, D. S., Mörschel, U., Schmidt, U., Tan, V., Tuitjer, F., Woyke, T., and Schiller, C.: Fast in situ stratospheric hygrometers: A new family of balloon-borne and airborne Lyman $\alpha$ photofragment fluorescence hygrometers, J. Geophys. Res., 104, 1807-1816, doi:10.1029/1998JD100025, 1999. 